\title{
Two- Year Survival Analysis and Factors influencing Survival of Acute Myocardial Infarction
}

\author{
Yasmine F. Siregar ${ }^{\star 1}$, Sutomo Kasiman ${ }^{1}$, Zainal Safri ${ }^{1}$, \\ Harris Hasan ${ }^{1}$, Abdul H. Reynaldo ${ }^{1}$, Faisal Habib ${ }^{1}$ \\ ${ }^{1}$ Department of Cardiology and Vascular Medicine, University of Sumatera Utara, \\ Adam Malik Hospital, Medan, Indonesia
}

\begin{abstract}
Background: Non-ST segment elevation myocardial infarction (NSTEMI) has less frequent complications, but has worse long-term prognosis than ST segment elevation myocardial infarction (STEMI). Mortality rates of NSTEMI were lower than STEMI but after 6 months both mortality were similar. The purpose of this study was to determine the 2-year survival in patients with acute myocardial infarction (AMI). Method: This cohort retrospective study included 264 AMI patients treated from January - December 2015 in H. Adam Malik Medan General Hospital. The study sample was divided based on the diagnosis of STEMI and NSTEMI. Data were obtained from medical records. All patients were contacted by phone to determine their condition 2 years after experiencing AMI. Multivariate analysis was performed to assess the factors that affect the survival. The 2-year survival of STEMI and NSTEMI was compared using the Kaplan Meier plot.Result: From 264 patients, there were $216(81.8 \%)$ men with median age of 56 years. We found 147 STEMI patients and 117 NSTEMI patients. NSTEMI group tended to have history of coronary artery disease, higher blood pressure, less revascularization, longer hospitalization days and less number of post AMI complications. Survival and mortality rates in 2 years were $58 \%$ and $28 \%$. Multivariate analysis showed higher blood pressure (OR 1.023, CI 95\%, 1.003 - 1.044) dan PCI during hospitalization (OR 8.604, CI 95\%, 2.264 32.702) showed better 2-year survival. There were no significant 2-year survival differences between the two groups (log rank 0.136). Better 2-year survival was found in patients with single vessel disease (log rank 0.001), patients who received revascularization (log rank 0.001) and patients who did not experience heart failure or cardiogenic shock during hospitalization (log rank 0.001). Conclusion: There was no difference in 2-year survival between STEMI and NSTEMI patients who were admitted to H. Adam Malik Medan General Hospital in 2015. The 2-year survival appeared better in patients with single vessel disease, received revascularization and did not experience heart failure or cardiogenic shock during hospitalization.
\end{abstract}

Keyword: survival, mortality, STEMI, NSTEMI.

Yasmine F. Siregar et al /International Journal of PharmTech Research, 2019,12(2): 119127.

DOI: http://dx.doi.org/10.20902/IJPTR.2019.120204 


\section{Introduction}

Cardiovascular disease (CVD) ranks the first cause of death worldwide. In 2008, 17.3 million people are estimated to have died from CVD. In Southeast Asia, the mortality rate rose to $24 \%$ and the disability rate was 26 million. ${ }^{1}$ Eighty percent of these deaths are caused by heart attacks and strokes, and three-quarters of events occur in low-middle income countries. ${ }^{2}$ As a non-communicable disease in Indonesia, coronary artery disease (CAD) is the third cause of death after stroke and diabetes mellitus (DM) at the age group of 45-54 years old. ${ }^{3}$

According to The Third Global MI Task Force, myocardial infarction is characterized by typical chest pain, electrocardiographic abnormalities, and increased cardiac enzymes. ${ }^{4}$ Based on these abnormalities, acute coronary syndrome (ACS) is divided into ST segment elevation myocardial infarction (STEMI), Non-ST segment elevation myocardial infarction (NSTEMI), and unstable angina pectoris. ${ }^{5}$ STEMI and NSTEMI are categorized as acute myocardial infarction (AMI).

TRIUMPH Registry reported the incidence of STEMI were 43 to 144 per 100,000 people per year. STEMI was often experienced by younger men and mortality was influenced by various factors, including advanced age, Killip class, time from onset of chest pain to treatment, presence of emergency systems, treatment, history of myocardial infarction, diabetes mellitus, and left ventricular ejection fraction. The morbidity was worse in patients with history of diabetes mellitus, hypertension, smoking, history of percutaneous coronary intervention / bypass surgery, kidney disorders and obesity. ${ }^{6}$ Meanwhile, NSTEMI occurred in $70 \%$ of all acute coronary syndrome cases and mostly experienced by older patients along with multiple comorbidities. Unlike STEMI who receive a more uniform guide to therapy, NSTEMI undergo a more diverse treatment method and inconsistent therapeutic behaviors in the use of invasive and conservative strategies that illustrate an uncertainty in the patient's initial evaluation and management. ${ }^{5,7}$

SLOVAKS Registry showed a decrease in mortality from acute coronary syndrome in the last 15 years. In STEMI and NSTEMI, death during hospitalization and in 30-days were between $5.99 \%-10.7 \%$ and $3.9 \%-7,65 \%{ }^{8,9}$ This can be caused by the transportation system, the availability of better and more modern reperfusion and pharmacotherapy therapy. In a survival analysis study conducted in Korea, the 30-days survival rate was $88 \%$, 1-year survival was $75 \%, 3$-years survival was $62 \%$ and 5 -years survival was $40 \%$. The highest mortality due to ACS is within the first 6 months. Initially, mortality of NSTEMI is lower than STEMI. But after 6 months, mortality both are similar and long-term mortality of NSTEMI is higher. ${ }^{5,7,10}$

Most survival studies were carried out in Europe, especially in central institutions or hospitals that provide cardiology intersive care or primary coronary intervention. These data did not illustrate the complications of ACS throughout the world, where there are still many patients died before contact with health system officials. The health system level, social background and patient education seem to influence mortality in certain places ${ }^{11}$. The aim of this study was to determine the 2-year survival in patients with acute myocardial infarction (AMI).

\section{Method}

\section{Population and Design}

This cohort retrospective study included 264 patients with AMI admitted to H. Adam Malik Medan General Hospital, Indonesia from January 2015 until December 2015. The inclusion criteria was AMI (STEMI and NSTEMI) patients hospitalized in H. Adam Malik General Hospital in 2015. STEMI was characterized by acute anginal chest pain, elevated cardiac enzyme, and new ST elevation at the J point in two contiguous leads with the cut-points $\geq 0.1 \mathrm{mV}$ in all leads other than leads V2-V3 where the following cut points apply $\geq 0.2 \mathrm{mV}$ in men $\geq 40$ years; $\geq 0.25 \mathrm{mV}$ in men $<40$ years, or $\geq 0.15 \mathrm{mV}$ in women. NSTEMI was characterized by acute anginal chest pain, elevated cardiac enzyme, and new horizontal or down-sloping ST depression $\geq 0.05 \mathrm{mV}$ in two contiguous leads and/or $\mathrm{T}$ inversion $\geq 0.1 \mathrm{mV}$ in two contiguous leads with prominent $\mathrm{R}$ wave or $\mathrm{R} / \mathrm{S}$ ratio $>1$. The exclusion criteria were patient could not be contacted and died after 2 years due to non-cardiovascular cause. Patients who met the inclusion and exclusion criteria were recruited as subjects. 
Patient's data such as profile, risk factors, previous disease, Killip class, GRACE score, ECG at admission, laboratory results, ejection fraction, angiography results, therapy, length of hospital stay, and complications were obtained from medical records. After 2 years, patients were contacted via telephone.

The patients were divided into 2 groups according to diagnosis (STEMI versus NSTEMI). Factors affecting survival was analysed. Survival after two years was compared between STEMI and NSTEMI.

\section{Statistical Analysis}

All statistical analyses were carried out using the SPSS statistical software, version 19.0. The data were presented with mean \pm SD or median and interquartile range for continuous variables. Categorical variables presented as percentage. The normality test for continuous variables in all study subjects using one sample Kolmogorov Smirnov ( $>$ 50). In continuous variables compared with two free samples $\mathrm{T}$ test (Two Samples Independent Student's t-test) on normal distributed data or Mann Whitney U Test if the data was not normally distributed. In categorical variables, an analytical test was performed using chi squared or fisher exact tests. Data with p value $<0.25$ would be included in multivariate analysis. Multivariate analysis was performed using logistic regression. The 2-year survival between STEMI and NSTEMI was compared using Kaplan Meier Plot and log rank test. The p value $<0.05$ was considered as statistically significant.

\section{Result}

From January 2015 - December 2015, there were 264 AMI patients admitted to Haji Adam Malik General Hospital, consisted of 147 (55.7\%) of STEMI and 117 (44.3\%) of NSTEMI. A total of 216 patients were male $(81.8 \%)$ with median age of 56 years old. Most common risk factor was smoking (68.9\%), followed by hypertension (62.5\%), dyslipidaemia (52.3\%), diabetes mellitus, and history of previous coronary artery disease (17.4\%). Most patients were admitted to the hospital with onset $>12$ hours $(75.4 \%)$ had high GRACE score (40.5\%) and Killip class I-II (82.2\%). Median blood pressure during admission was 130/80 $\mathrm{mmHg}$. Glomerular filtration rate was normal (average $77.13 \mathrm{mg} / \mathrm{ml}$ ). Troponin $\mathrm{T}$ level was $0.645 \mathrm{mg} / \mathrm{dl}$ and CKMB level was $58 \mathrm{U} / \mathrm{L}$. In 89\% patients, there was no arrhythmia at ECG on admission.

Coronary angiography was performed in 146 patients. Most STEMI patients had single vessel disease, while NSTEMI patient mostly presented with three-vessel disease. From 146 patients, only 76 patients underwent PCI. There was difference in inotropic and nitrate use between STEMI and NSTEMI. Enoxaparin was the anticoagulant that was mostly administered in STEMI. NSTEMI had longer hospitalization days. The most common complication after myocardial infarction was heart failure, which was higher in STEMI.

Two years following AMI, we found 153 patients alive and 75 patients died. There were 101 STEMI patients and 52 NSTEMI patients survived. We found survival and mortality rate after 2 years were $28 \%$ and $58 \%$, respectively.

Table 1. Baseline Characteristic of Subject Study

\begin{tabular}{lccc}
\hline \multirow{2}{*}{ Characteristic } & \multicolumn{2}{c}{ AMI classification } & \multirow{2}{*}{$\boldsymbol{p}$} \\
\cline { 2 - 3 } & $\begin{array}{c}\text { STEMI } \\
\mathbf{n}=\mathbf{1 4 7}\end{array}$ & $\begin{array}{c}\text { NSTEMI } \\
\mathbf{n = 1 1 7}\end{array}$ & \\
\hline Gender & & & \\
Male & $124(57,4 \%)$ & $92(42,6 \%)$ & 0,231 \\
Female & $23(47,9 \%)$ & $25(52,1 \%)$ & \\
\hline Age (year) & $56,26 \pm 0,822$ & $58,37 \pm 0,903$ & 0,135 \\
\hline Comorbidities and risk factors, yes & & & \\
Hypertension & $86(52,1 \%)$ & $79(47,9 \%)$ & 0,133 \\
Coronary artery disease & $17(37,0 \%)$ & $29(63,0 \%)$ & $0,005^{*}$ \\
Diabetes mellitus & $53(50,0 \%)$ & $53(50,0 \%)$ & 0,128 \\
Stroke & $3(27,3 \%)$ & $8(72,7 \%)$ & 0,066 \\
Chronic kidney disease & $8(32,0 \%)$ & $17(68,0 \%)$ & $0,012^{*}$ \\
Dyslipidaemia & $64(46,4 \%)$ & $74(53,6 \%)$ & $0,001^{*}$ \\
History of smoking & $103(56,6 \%)$ & $79(43,4 \%)$ & $0,657$. \\
& & & \\
\hline
\end{tabular}




\begin{tabular}{|c|c|c|c|}
\hline \multicolumn{4}{|l|}{ Body mass index } \\
\hline Underweight & $1(25,0 \%)$ & $3(75,0 \%)$ & \multirow[t]{4}{*}{0,262} \\
\hline Normal & $46(63,9 \%)$ & $26(36,1 \%)$ & \\
\hline Overweight & $59(52,7 \%)$ & $53(47,3 \%)$ & \\
\hline Obese & $41(53,9 \%)$ & $35(46,1 \%)$ & \\
\hline \multicolumn{4}{|l|}{ Onset } \\
\hline$\leq 12$ hours & $36(55,4 \%)$ & $29(44,6 \%)$ & \multirow[t]{2}{*}{0,956} \\
\hline$>12$ hours & $111(55,8 \%)$ & $88(44,2 \%)$ & \\
\hline \multicolumn{3}{|l|}{ TIMI risk } & \multirow{3}{*}{0,660} \\
\hline Low risk & $84(54,5 \%)$ & $70(45,5 \%)$ & \\
\hline High risk & $63(57,3 \%)$ & $47(42,7 \%)$ & \\
\hline \multicolumn{4}{|l|}{ GRACE score } \\
\hline Low $(\leq 88)$ & $22(42,3 \%)$ & $30(57,7 \%)$ & \multirow{3}{*}{0,066} \\
\hline Moderate (89-118) & $65(61,9 \%)$ & $40(38,1 \%)$ & \\
\hline $\operatorname{High}(>118)$ & $60(56,1 \%)$ & $47(43,9 \%)$ & \\
\hline \multicolumn{4}{|l|}{ Killip class } \\
\hline $1-2$ & $117(53,9 \%)$ & $100(46,1 \%)$ & \multirow[t]{2}{*}{0,215} \\
\hline $3-4$ & $30(63,8 \%)$ & $17(36,2 \%)$ & \\
\hline \multicolumn{4}{|l|}{ Haemodynamic } \\
\hline Heart rate, $\mathrm{x} /$ minute & $84,176 \pm 1,707$ & $88,247 \pm 2,319$ & \multirow{3}{*}{$\begin{array}{c}0,576 \\
0,001 * \\
0,001 *\end{array}$} \\
\hline Systolic blood pressure, $\mathrm{mmHg}$ & $120,07 \pm 1,994$ & $132,05 \pm 2,489$ & \\
\hline Diastolic blood pressure, $\mathrm{mmHg}$ & $75,714 \pm 1,236$ & $83,076 \pm 1,365$ & \\
\hline \multicolumn{4}{|l|}{ Laboratory } \\
\hline Hemoglobin, g/dl & $16,13 \pm 1,752$ & $14,06 \pm 0,237$ & \multirow{5}{*}{$\begin{array}{c}0,107 \\
0,003 * \\
0,013 * \\
0,001 * \\
0,001 *\end{array}$} \\
\hline Creatinin, $\mathrm{mg} / \mathrm{ml}$ & $1,083 \pm 0,058$ & $1,16 \pm 0,065$ & \\
\hline Glomerular filtration rate, $\mathrm{mg} / \mathrm{dl}$ & $77,67 \pm 34,84$ & $67,17 \pm 32,48$ & \\
\hline Troponin $\mathrm{T}, \mathrm{ng} / \mathrm{ml}$ & $1,04 \pm 0,083$ & $0,63 \pm 0,075$ & \\
\hline $\mathrm{CKMB}, \mathrm{U} / \mathrm{L}$ & $133,43 \pm 14,94$ & $61,72 \pm 8,60$ & \\
\hline \multicolumn{3}{|l|}{ Electrocardiography at admission } & \multirow{5}{*}{0,130} \\
\hline Malignant VES & $4(50,0 \%)$ & $4(50,0 \%)$ & \\
\hline Tachyarrhythmia & $3(33,3 \%)$ & $6(66,7 \%)$ & \\
\hline Bradyarrhythmia & $10(83,3 \%)$ & $2(16,7 \%)$ & \\
\hline No arrhythmia & $130(55,3 \%)$ & $105(44,7 \%)$ & \\
\hline \multicolumn{4}{|l|}{ Ejection fraction } \\
\hline$<40 \%$ & $72(56,3 \%)$ & $56(43,8 \%)$ & \multirow[t]{2}{*}{0,857} \\
\hline$\geq 40 \%$ & $75(55,1 \%)$ & $61(44,9 \%)$ & \\
\hline Coronary angiography & $87(59,6 \%)$ & $59(40,4 \%)$ & 0,190 \\
\hline \multicolumn{3}{|l|}{ No. of affected vessel } & 0214 \\
\hline $1 \mathrm{VD}$ & $34(68 \%)$ & $16(32 \%)$ & 0,314 \\
\hline $2 \mathrm{VD}$ & $25(62,5 \%)$ & $15(37,5 \%)$ & \\
\hline $3 \mathrm{VD}$ & $19(44,2 \%)$ & $24(55,8 \%)$ & \\
\hline 2VD+LM & $3(75,0 \%)$ & $1(25,0 \%)$ & \\
\hline 3VD+LM & $3(50,0 \%)$ & $3(50,0 \%)$ & \\
\hline Not significant & $3(60,0 \%)$ & $2(40,0)$ & \\
\hline Unknown & $60(51,7 \%)$ & $56(48,2 \%)$ & \\
\hline Revascularization, yes & & & \\
\hline PCI & $49(64,5 \%)$ & $27(35,5 \%)$ & \\
\hline Fibrinolysis & $8(100,0 \%)$ & $0(0,0 \%)$ & $0,004^{*}$ \\
\hline No reperfusion & $90(50,0 \%)$ & $90(50,0 \%)$ & \\
\hline Therapy, yes & & & \\
\hline Inotropic & $44(71,0 \%)$ & $18(29,0 \%)$ & $0,006^{*}$ \\
\hline Aspilet & $145(56,2 \%)$ & $113(43,8 \%)$ & 0,265 \\
\hline Clopidogrel & $142(55,3 \%)$ & $115(44,7 \%)$ & 0,395 \\
\hline Beta Blocker & $77(52,7 \%)$ & $69(47,3 \%)$ & 0,284 \\
\hline Nitrate & $111(50,9 \%)$ & $107(49,1 \%)$ & $0,001^{*}$ \\
\hline ACEi/ARB & $79(55,6 \%)$ & $63(44,4 \%)$ & 0,323 \\
\hline Statin & $142(55,5 \%)$ & $114(44,5 \%)$ & 0,693 \\
\hline
\end{tabular}




\begin{tabular}{lccc}
\hline Anticoagulant & & & \\
UFH & $20(42,6 \%)$ & $27(57,4 \%)$ & $0,008^{*}$ \\
Enoxaparin & $63(60,6 \%)$ & $41(39,4 \%)$ & \\
Fondaparinux & $55(52,9 \%)$ & $49(47,1 \%)$ & \\
No anticoagulant & $9(100 \%)$ & $0(0,0 \%)$ & $0,025^{*}$ \\
\hline Days of hospitalization, days & $6,70 \pm 0,266$ & $7,27 \pm 0,286$ & $0,036^{*}$ \\
\hline Complication & & & \\
Heart failure & $19(51,4 \%)$ & $18(48,6 \%)$ & \\
Cardiogenic shock & $14(73,7 \%)$ & $5(26,3 \%)$ & \\
Bleeding & $0(0,0 \%)$ & $3(100,0 \%)$ & \\
Arrhythmia & $11(64,7 \%)$ & $6(35,3 \%)$ & \\
Stroke & $0(0,0 \%)$ & $1(100,0 \%)$ & \\
In-hospital death & $19(76,0 \%)$ & $6(24,0 \%)$ & \\
No complication & $84(51,9 \%)$ & $78(48,1 \%)$ & \\
\hline
\end{tabular}

After adjusting admission variables by univariate analysis, we performed multivariate analysis to find out which independent variable was the most dominant and influence the 2-year survival (Table 2). Based on the analysis, higher systolic blood pressure on admission and PCI were two of the strongest factors that influence better long-term outcome for both STEMI and NSTEMI.

Table 2. Two-year survival based on diagnosis

\begin{tabular}{cccc}
\hline \multirow{2}{*}{ Diagnosis } & \multicolumn{2}{c}{ 2-year survival } & \multirow{2}{*}{ Total } \\
\cline { 2 - 3 } & Alive & Died & \\
\hline STEMI & 101 & 40 & 141 \\
\hline NSTEMI & 52 & 35 & 87 \\
\hline Total & 153 & 75 & 228 \\
\hline
\end{tabular}

Table 3. Multivariate Analysis of Factors Influencing 2-Year Survival

\begin{tabular}{lccccc}
\hline \multicolumn{1}{c}{ Variable } & B & Wald & p & OR & CI 95\% \\
\hline Coronary artery disease & $-0,814$ & 2,893 & 0,089 & 0,443 & $0,173-1,132$ \\
\hline Systolic blood pressure & $-0,018$ & 5,329 & $0,021^{*}$ & 1,023 & $1,003-1,044$ \\
\hline Revascularization & & & & & \\
$\quad$ PCI & 2,152 & 9,981 & $0,002 *$ & 8,604 & $2,264-32,702$ \\
$\quad$ Fibrinolysis & 1,380 & 1,140 & 0,286 & 3,976 & $0,316-50,096$ \\
\hline Number of vessel affected & & & & & \\
$\quad$ Single vessel & $-1,224$ & 2,311 & 0,128 & 0,294 & $0,061-1,425$ \\
$\quad$ Multi vessel & -0.184 & 0,044 & 0,834 & 0,832 & $1,48-4,66$ \\
\hline Complication & & & & & \\
$\quad$ Heart failure & 22,090 & 0,000 & 0,998 & 39,540 & 0,000 \\
$\quad$ Cardiogenic shock & 20,776 & 0,000 & 0,998 & 10,735 & 0,000 \\
$\quad$ Bleeding & 20,414 & 0,000 & 0,998 & 73,122 & 0,000 \\
$\quad$ Arrhythmia & 23,427 & 0,000 & 0,997 & 14,883 & 0,000 \\
$\quad$ Stroke & 41,614 & 0,000 & 0,999 & 11,000 & 0,000 \\
\hline
\end{tabular}

We conducted analysis survival based on diagnosis, type of revascularization, number of coronary arteries involved, and complications. STEMI patients had higher mortality rate within the first year and better survival in the second year. Conversely, patients with NSTEMI had lower mortality rates in the first year compared to STEMI but worse mortality in the following year. The difference in mortality between both groups was not significant (Log Rank 0.136). Also, patients complicated by cardiogenic shock had the highest mortality within 2 years, followed by heart failure and arrhythmia (Log Rank 0.001). 
It appeared that patients with coronary angiography results showing no significant stenosis or single vessel disease had better 2-year survival. Outcomes of patients with multivessel disease improved from 0-24 months after experiencing AMI. Patients who did not undergo coronary angiography had worst survival, where the survival rate decreased in 0-3 months and continued to decline until the next 24 months. This study showed that patients with multivessel disease had higher mortality rate within 2 years (Log Rank 0.001).

Patients who did not receive reperfusion therapy had progressively lower survival rate from the first to the second year. Patients who received fibrinolysis agent had better survival rate within the first 6 months and declined steadily until the second year. Although within the first 6 months the survival rate was lower, patients treated with PCI subsequently had higher survival rates compared to fibrinolysis until the second year ( $\log$ Rank 0.001).

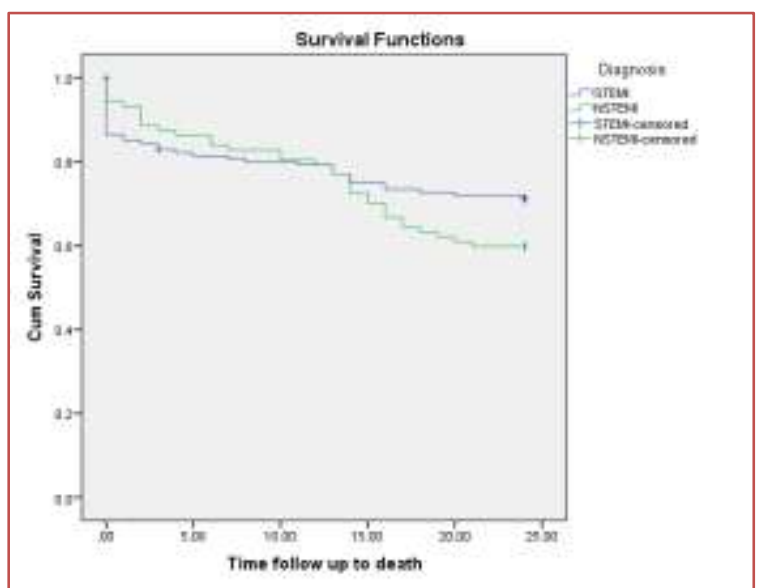

Figure 1. Kaplan Meier Curve of 2-year survival between STEMI and NSTEMI (Log Rank 0.136)

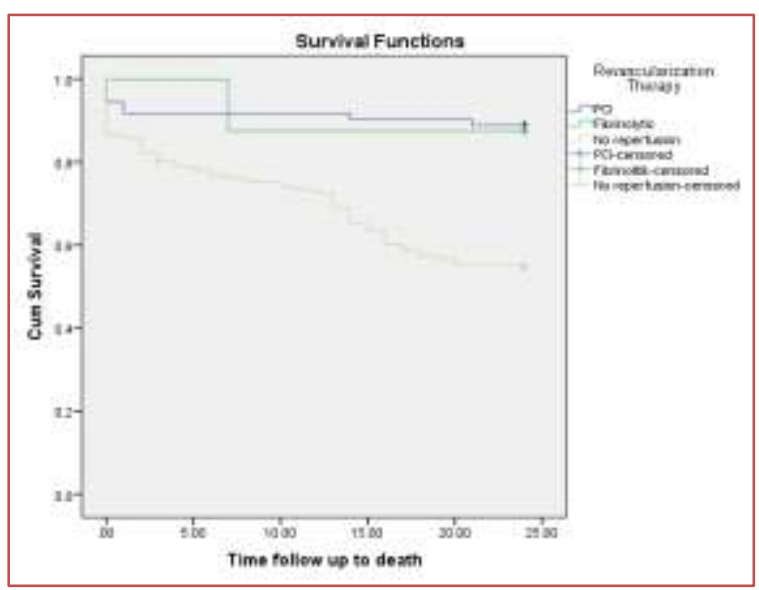

Figure 3. Kaplan Meier Curve of 2-year survival in patients treated with PCI, fibrinolytic or without reperfusion (Log Rank 0.001)

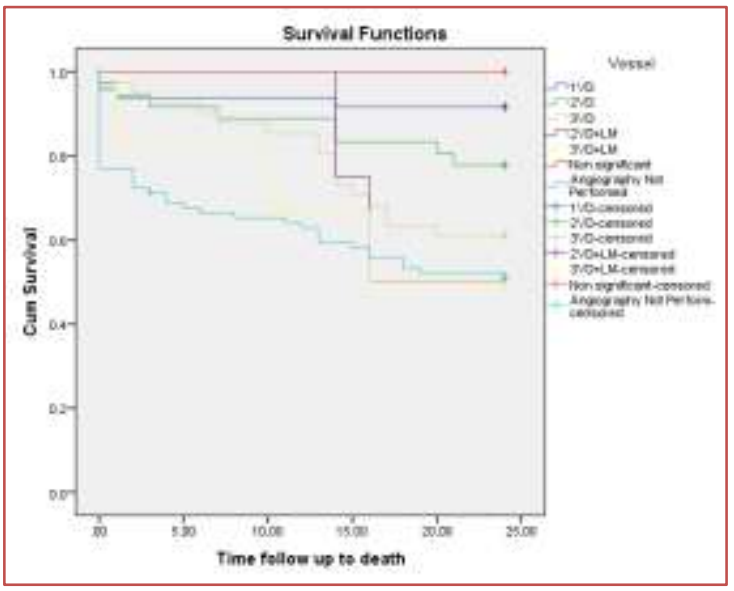

Figure 2. Kaplan Meier Curve of 2-year survival based on coronary artery lesion (Log Rank 0.001)

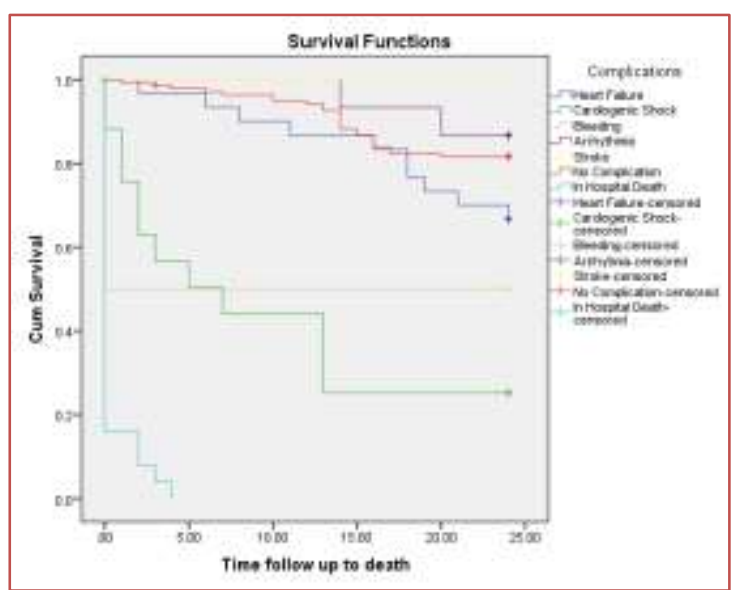

Figure 4. Kaplan Meier Curve of 2-year survival in patients with or without complications (such as heart failure, cardiogenic shock, bleeding, arrhythmia and stroke) (Log Rank 0.001). 


\section{Discussion}

In 2015, there were 264 patients admitted to H. Adam Malik General Hospital due to AMI. 55.7\% were diagnosed with STEMI (55.7\%) and 44.3\% were diagnosed with NSTEMI. In 2007, Montalescot found a higher percentage of STEMI (70.8\%), mostly male with average age of $64 \pm 14$ years. Most common risk factors were history of smoking (68.9\%), hypertension (62.5\%) and dyslipidemia (52.3\%). This is similar with other study in France showing the most common risk factors were dyslipidemia (49.7\%), hypertension $(47.1 \%)$ and smoking history (36.6\%). Between STEMI and NSTEMI, there were no difference in onset of chest pain to hospital presentation, Killip class, TIMI Risk and GRACE score ( $p$ value $0.956 ; p$ value 0.215; $p$ value 0.66; $\mathrm{p}$ value 0.066). This study found higher systolic and diastolic blood pressure at admission in NSTEMI ( $\mathrm{p}$ value 0.001 and $\mathrm{p}$ value 0.001 ). Other study found only systolic blood pressure was significantly different ( $\mathrm{p}$ value 0.001$).{ }^{12}$

STEMI received more revascularization (PCI and fibrinolysis) than NSTEMI (64.4\% vs $35.5 \%$ and $100 \%$ vs $0 \%$; p value 0.004). Inotropic and nitrate were more commonly administered for STEMI rather than NSTEMI ( $p$ value 0.001). This is because more STEMI patients presented with lower systolic blood pressure (Killip IV). Tarvasmäki found that STEMI was the most common cause of cardiogenic shock, but there was no difference in inotropic use between STEMI and NSTEMI. ${ }^{13}$

Two years follow up was conducted in 264 patients. 147 STEMI patients and 117 NSTEMI patients were alive, 36 patients were lost to follow up. STEMI had higher mortality in the first year and lower mortality in the second year. On the contrary, NSTEMI patients had lower mortality in the first year bur higher mortality during the second year. The mortality rate increased in the first year, so mortality rate for STEMI and NSTEMI were almost the same, namely $8-10 \%$. Worse long term mortality in NSTEMI might be caused by older age and comorbid factors more commonly occurred in NSTEMI patients. ${ }^{12,14,15}$

Survival rate were better in patients receiving revascularization therapy (PCI or fibrinolysis). Hyunh et al found that primary PCI reduced short-term and long-term mortality of $34 \%$ and $24 \% .{ }^{16}$ WIRE Registry stated that primary PCI is the only choice of revascularization that could reduce long-term mortality rate. ${ }^{17}$ Meanwhile, STEPP-AMI trial in India failed to show different outcome in patients treated with fibrinolysis or primary PCI (3.9\% vs $11.1 \%$; p value 0.07$){ }^{18}$

Re-infarction, stroke, cardiovascular death and long-term mortality increased according to the severity of coronary lesion. Cumulative risk after myocardial infarction was $26.4 \%$ in patients with left main artery disease. Incidence of infarction, stroke and cardiovascular death increased was worse in multiple coronary artery disease, but worse in patients who did not undergo coronary angiography. ${ }^{19}$

Cardiogenic shock and heart failure were two of the most common complications and both had low survival rate. In cardiogenic shock group, survival decreased by $50 \%$ within 2 years. Meanwhile in heart failure, reduction of survival in 2 years was $25 \%$. Previous studies showed that 30-day and 30-day to 1-year mortality rate after AMI complicated by cardiogenic shock were $39.7 \%-46.7 \%$ and $6.6 \%-12.3 \%$. Risk of death after AMI complicated by heart failure was 5.98 times higher than those without heart failure (HR 5.98; $95 \%$ CI: $5.39-6.64)$.

\section{Limitation of Study}

This has several limitations. Since this is a retrospective study, there were some difficulties faced during data collection. Number of samples was small and carried out in only one center. For comparison, further research can be continued with larger number of samples and performed in multiple centers.

\section{Conclusions}

There was no difference in 2-year survival between STEMI and NSTEMI patients who were admitted to H. Adam Malik Medan General Hospital in 2015. The 2-year survival appeared better in patients with higher blood pressure at admission, single vessel disease, received revascularization and did not experience heart failure or cardiogenic shock during hospitalization. 


\section{References}

1. Braunwald, E., Bonow, R.O., Mann, D.L., et al. 2012. Braunwald's Heart Disease: A Textbook of Cardiovascular Medicine. $9^{\text {th }}$ ed. Philadelphia: Elsevier Saunders.

2. World Health Organization. 2014. Global Health Estimates: Deaths by Cause, Age, Sex And Country, 2000-2012. Geneva: World Health Organization. Available from: http://www.who.int/mediacentre/factsheets/fs310/en/

3. Departemen Kesehatan Republik Indonesia. 2008. Riset Kesehatan Dasar. Jakarta: Badan Penelitian dan Pengembangan Departemen Kesehatan Republik Indonesia. Available from: http://www.depkes.go.id/article/view/17073100005/penyakit-jantung-penyebab-kematian-tertinggikemenkes-ingatkan-cerdik-.html

4. Thygesen K, Alpert JS, Jaffe AS, et al. Third universal definition of myocardial infarction. Circulation. 2012;126:2020-2035, doi:10.1161/CIR.0b013e31826e1058

5. Irmalita, Juzar, D.A., Andrianto, et al. 2015. Pedoman Tatalaksana Sindrom Koroner Akut. Edisi Ketiga. Jakarta: Perhimpunan Dokter Spesialis Kardiovaskular Indonesia. Available from: http://www.inaheart.org/upload/file/Pedoman_tatalaksana_Sindrom_Koroner_Akut_2015.pdf

6. Arnold SV, Smolderen, KG, Kennedy KF, et al. Risk factors for rehospitalization for acute coronary syndromes and unplanned revascularization following acute myocardial infarction. Journal of the American Heart Association, 2015 Feb;9;4(2) doi:10.1161/JAHA.114.001352.

7. Chang H, Min JK, Rao SV, et al. Non-ST-Segment Elevation Acute Coronary Syndromes: Targeted Imaging to Refine Upstream Risk Stratification. Circulation: Cardiovascular Imaging. 2012 Jul;5(4):536-46.

8. Kovár F, Studenčan M, Hricák V, et al. Current trends in management of NSTE-ACS patients in the Slovak Republic. Analysis of the SLOVAKS-2 registry from 2011. Cardiology Letters. 2014;23(2):115-125.

9. Studenčan M, Hricák V, Kováŕ F, et al. Current trends in management of STEMI in the Slovak Republic. The analysis of the SLOVAKS-2 registry from 2011, Cardiology Letters. 2013;22(2):115124.

10. Ren L, Ye H, Wang P, et al. Comparison of long-term mortality of acute ST-segment elevation myocardial infarction and non-ST-segment elevation acute coronary syndrome patients after percutaneous coronary intervention. International Journal of Clinical and Experimental Medicine. 2014; 7(12): 5588-5592.

11. Studenčan M, Kovář F, Hricák V, et al. Two-year survival of STEMI patients in Slovakia. An analysis of the SLOVak registry of Acute Coronary Syndromes (SLOVAKS). Cor et vasa. 2014;56:e297-e303

12. Montalescot G, Dallongeville J, Van Belle E, et al. STEMI and NSTEMI: are they so different? 1 year outcomes in acute myocardial infarction as defined by the ESC/ACC definition (the OPERA registry). European Heart Journal. 2007 Jun;28(12):1409-17

13. Tarvasmäki T, Lassus J, Varpula M. Current real-life use of vasopressors and inotropes in cardiogenic shock - adrenaline use is associated with excess organ injury and mortality. Critical Care. $2016 \mathrm{Jul}$ 4;20(1):208.

14. Roe MT, Messenger JC, Weintraub WS, et al. Treatments, trends, and outcomes of acute myocardial infarction and percutaneous coronary intervention. Journal of the American College of Cardiology. 2010 Jul 20;56(4):254-63.

15. Yan AT, Tan M, Fitchett D, et al. One-year outcome of patients after acute coronary syndromes (from the Canadian Acute Coronary Syndromes Registry). American Journal of Cardiology. 2005 Feb 1;95(3):438.

16. Huynh T, Perron S, O'Loughlin J, et al. Comparison of primary percutaneous coronary intervention and fibrinolytic therapy in ST-segment-elevation myocardial infarction: bayesian hierarchical metaanalyses of randomized controlled trials and observational studies. Circulation. 2009 Jun 23;119(24):3101-9

17. Grajek S, Lesiak M, Araszkiewicz A, et al. Short- and long- term mortality in patients with STelevation myocardial infarction treated with different therapeutic strategies. Results from WIelkopolska REgional 2002 Registry (WIRE Registry). Kardiologia Polska. 2008 Feb;66(2):15463.

18. Victor SM, Subban V, Alexander T, et al. A prospective, observational, multicentre study comparing 
tenecteplase facilitated PCI versus primary PCI in Indian patients with STEMI (STEPP-AMI). Open Heart. 2014 Aug 20;1(1):e000133.

19. Özcan C, Deleskog A, Olsen AMS, et al. Coronary artery disease severity and long-term cardiovascular risk in patients with myocardial infarction: a Danish nationwide register-based cohort study. European Heart Journal - Cardiovascular Pharmacotherapy. 2018 Jan 1;4(1):25-35.

20. Sulo G, Igland J, Nygard O, et al. Prognostic Impact of In-Hospital and Postdischarge Heart Failure in Patients With Acute Myocardial Infarction: A Nationwide Analysis Using Data From the Cardiovascular Disease in Norway (CVDNOR) Project. Journal of the American Heart Association. 2017 Mar 15;6(3). 